\title{
Dietary patterns of women aged 50-69 years and associations with nutrient intake, sociodemographic factors and key risk factors for non-communicable diseases
}

\author{
Marianne S Markussen 1, Marit B Veierød ${ }^{1,2}$, Anne Lene Kristiansen ', Giske Ursin 1,3,4,* \\ and Lene F Andersen ${ }^{1}$ \\ ${ }^{1}$ Institute of Basic Medical Sciences, Department of Nutrition, University of Oslo, Blindern, Oslo, Norway: ${ }^{2}$ Institute of \\ Basic Medical Sciences, Department of Biostatistics, Center for Biostatistics and Epidemiology, University of Oslo, \\ Blindern, Oslo, Norway: ${ }^{3}$ Cancer Registry of Norway, PO Box 5313 Majorstuen, 0304 Oslo, Norway: \\ ${ }^{4}$ Department of Preventive Medicine, University of Southern California, Los Angeles, CA, USA
}

Submitted 3 June 2015: Final revision received 14 October 2015: Accepted 20 November 2015: First published online 19 January 2016

\begin{abstract}
Objective: In women, the risk for non-communicable diseases increases after menopause. We aimed to identify major dietary patterns and study their associations with nutrient intake, sociodemographic factors and risk factors for non-communicable diseases among women aged 50-69 years.

Design: A cross-sectional study. Food intake was recorded by a 253-item FFQ. Dietary patterns were identified using principal component analysis. The associations between the dietary patterns and nutrients were described by Pearson's correlation coefficients and multiple regression analysis was used to examine the associations between the dietary patterns and age, education, BMI, physical activity and smoking.

Setting: The Norwegian Breast Cancer Screening Programme.

Subjects: Women ( $n$ 6298) aged 50-69 years.

Results: Three dietary patterns were identified: 'Prudent', 'Western' and 'Continental'. Adherence to the 'Prudent' pattern was related to older age, higher education, higher BMI, more physical activity $\left(P_{\text {trend }}<0.001\right)$ and being a non-smoker $(P<0 \cdot 001)$. Adherence to the 'Western' pattern was related to older age, lower education, higher BMI, less physical activity $\left(0.001 \leq P_{\text {trend }} \leq 0.006\right)$ and lower alcohol intake $(r=-0 \cdot 28)$. Adherence to the 'Continental' pattern was related to younger age, higher education, higher BMI, less physical activity, $\left(P_{\text {trend }}<0 \cdot 001\right)$, being a smoker $(P<0 \cdot 001)$ and higher alcohol intake $(r=0.36)$. Conclusions: Three distinct dietary patterns were identified. High adherence to a 'Prudent' pattern was associated with a healthy lifestyle, while high adherence to a 'Western' or 'Continental' pattern was associated with an unhealthy lifestyle. These findings are valuable knowledge for health authorities when forming strategies to promote a healthier lifestyle among women.
\end{abstract}

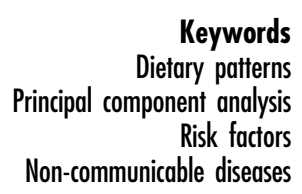

The rapidly growing burden of non-communicable diseases (NCD) represents a major health challenge to global economic and social development ${ }^{(1)}$. The four main types of NCD are CVD, cancers, chronic respiratory diseases and diabetes ${ }^{(2)}$. Key risk factors are diet, physical activity, obesity, smoking and alcohol intake. The WHO Global Strategy on Diet, Physical Activity and Health aims to promote and protect health by enabling communities to reduce disease and death rates related to unhealthy diet and physical inactivity ${ }^{(3)}$. In 2006 the European Food Safety Authority's Panel on Dietetic Products, Nutrition and Allergies established food-based dietary guidelines in order to provide the public with recommendations for a healthy $\operatorname{diet}^{(4)}$. The Panel defined seven steps for developing food-based dietary guidelines, one of these steps being the identification of food consumption patterns $^{(4)}$, also known as dietary patterns.

People consume foods and nutrients in different combinations, and analysing food consumption as dietary patterns is a complementary method to the traditional methods that focus on single nutrients and foods. By studying food synergy, the interaction between different foods ${ }^{(5)}$, one might better understand the relationship between food consumption and health ${ }^{(6-9)}$. There is a 
unique dietary culture in every country that may be reflected in the dietary patterns. Therefore, identification and characterization of major dietary patterns in a population, and how these patterns are associated with sociodemographic factors and key risk factors for NCD, represent important knowledge for health authorities when forming strategies to promote a healthier diet and lifestyle. Such information may also be useful for epidemiologists who are trying to untangle the role of diet from that of confounding factors. Many NCD could be prevented by modifying diet and lifestyle factors. In the present study we took advantage of a nationwide screening programme to study dietary patterns among women in postmenopausal age $e^{(10,11)}$ and identify how the dietary patterns are associated with sociodemographic factors and key risk factors for NCD.

\section{Methods}

\section{Study sample}

The Norwegian Breast Cancer Screening Programme is a governmentally funded national screening programme administered by the Cancer Registry of Norway ${ }^{(12)}$. All Norwegian women aged 50-69 years are invited to a bilateral two-view mammogram biennially. The participation rate is $77 \%{ }^{(13)}$, with about 250000 women invited per year. In 2006/2007, the Norwegian Breast Cancer Screening Programme's invitation letter for mammographic screening included a question on willingness to complete a dietary questionnaire. A total of 67527 women agreed to participate. In 2008, a consent form and an FFQ were sent to a random sample of 10000 of these women living all over Norway. A total of 6974 returned the FFQ. We excluded 676 women because the FFQ was not filled in ( $n$ 46) or because of missing data on height and/or weight ( $n$ 158), age ( $n$ 5), smoking status ( $n$ 41), education ( $n$ 79), physical activity ( $n$ 104), improbable height and weight ( $n$ 20, of which seven with self-reported height $<125 \mathrm{~cm}$ and thirteen with self-reported weight $<30 \mathrm{~kg}$ or $>170 \mathrm{~kg}$ ), age not within the range 50-69 years ( $n$ 15), BMI $<15.0 \mathrm{~kg} / \mathrm{m}^{2}$ or $>50.0 \mathrm{~kg} / \mathrm{m}^{2}(n$ 4) and with an energy intake $<2100 \mathrm{~kJ} / \mathrm{d}$ or $>15000 \mathrm{~kJ} / \mathrm{d}$ ( $n$ 204). This left us with a total sample of 6298 women.

\section{Dietary assessment}

The 16-page, 253-item FFQ was designed to capture the habitual food intake among Norwegian adults the preceding year, with an extra focus on fruit, vegetables, antioxidant-rich foods and beverages. It was based on a previously validated 180 -item FFQ designed to measure the total energy intake in the Norwegian population ${ }^{(14)}$, which later was expanded to a 270-item FFQ to cover the most antioxidant-rich foods and beverages in Norway ${ }^{(15)}$. The energy and food intakes estimated from the 270-item FFQ have been validated. The energy intake was evaluated against independent measures of energy expenditure using the ActiReg $^{\circledR}$ system (motion detection) ${ }^{(16)}$, whereas $7 \mathrm{~d}$ weighed food records were used to study the relative validity of food and nutrient intakes ${ }^{(15,17)}$. The correlation coefficient between energy intake and energy expenditure was 0.54. Correlations between the FFQ and weighed food records were 0.41 for berries, 0.61 for fruit and 0.38 for vegetables ${ }^{(15)}$. This FFQ has also been validated for ranking individuals according to their usual intake of fruit, juice and vegetables by using the method of triads with two independent and specific biomarkers of fruit and vegetables and $7 \mathrm{~d}$ weighed food records ${ }^{(17)}$. The validity coefficients ranged from 0.60 to 0.94 . The 253-item FFQ used in the present study was revised from the original 270-item FFQ by removing seventeen items that were seldom or never eaten (curly kale, red cabbage, mushrooms, globe artichoke, sundried tomatoes, tofu, cumin, turmeric, ginger powder, caraway, cloves, piri piri, sage, rosehip tea, organic blueberry juice, organic blackcurrant juice, crowberry juice).

For each food item, participants indicated their frequency of consumption ranging from never/seldom to several times per day. The portion size per consumption was asked in household units such as slices, glasses, cups, pieces, spoons and teaspoons. When a respondent only reported the frequency, but not the portion size, the food item was given the smallest portion size. If only the amount of the food item was given, the food item was considered as not used. The questionnaire also collected information about dietary supplements, age, height, weight, smoking, physical activity, illnesses and medication. Daily intakes of energy, nutrients and foods were computed using the food database AE-07 and KBS software system (KBS, version 4.9 2008) developed at the Department of Nutrition, University of Oslo, Norway. The food database AE-07 is based on the 2006 edition of the Norwegian food composition table (www.norwegian foodcomp.no). Intakes from dietary supplements were included in the calculations.

The 253 food items were categorized into forty-nine food groups based on similarity in ingredients, nutrient profile or culinary usage (see online supplementary material, Supplemental Table 1).

\section{Physical activity assessment}

Physical activity was assessed using a modified version ${ }^{(18)}$ of the physical activity questionnaire used in the California Teachers Study ${ }^{(19)}$. Participants were asked to assess habitual weekly physical activity and report all physical activity lasting at least $10 \mathrm{~min}$ per session. They were provided examples of light activities (defined as walking or crosscountry skiing at a slow pace), moderate activities (defined as activities where some effort is required and which cause increased breathing, such as bicycling, swimming or crosscountry skiing at a moderate pace, jogging at a slow pace, dancing) and strenuous activities (defined as activities that 
require hard effort and cause substantially increased breathing, such as aerobics, running, cross-country skiing or bicycling at a brisk pace). The women were asked to estimate their mean hours per week (none, <0.5, 0.5-1.0, $1 \cdot 5-2,2 \cdot 5-3 \cdot 5,4-6, \geq 7 \mathrm{~h}$ ) of participation at each level of activity. We created separate light, moderate and strenuous activity variables in minutes per week by summing up hours per week for each level of activity multiplied by 60 . We also calculated a variable indicating energy expenditure by multiplying the number of hours of each physical activity by its estimated metabolic cost ${ }^{(20)}$ and expressed this variable in metabolic equivalents of task (MET-h/week).

\section{Statistical methods}

Descriptive statistics were used to summarize characteristics of the study sample.

Principal component analysis (PCA) was used to derive dietary patterns based on the correlation matrix of the forty-nine food groups. Prior to extracting components, the suitability for using PCA was assessed by the KaiserMeyer-Olkin measure of sampling adequacy and Bartlett's test of sphericity, which tests whether our correlation matrix is significantly different from an identity matrix ${ }^{(21)}$. The Kaiser-Meyer-Olkin value was $0 \cdot 76$, which is above the suggested minimum of $0.50^{(22)}$, and Bartlett's test of sphericity was significant $(P<0 \cdot 001)$, supporting the suitability of the data for PCA. The input variables were standardized by using the correlation matrix of the forty-nine food group variables in the PCA, and not the covariance matrix. To determine the number of meaningful components to retain, we considered the eigenvalue $=1$ criterion, the scree test, the proportion of variance accounted for and the interpretability of the patterns ${ }^{(6)}$. For interpretation purposes, Varimax rotation was performed on the retained components. We considered food groups with a factor loading of $\geq 0 \cdot 3$ (absolute value) to load on that component. Finally, each woman's score was calculated for each of the retained components. We interpreted the retained components as dietary patterns and labelled them according to the more or less healthy combinations of food groups.

The associations between the identified dietary patterns and selected micro- and macronutrients were estimated by Pearson correlation coefficients $(r)$. We estimated 95\% confidence intervals based on 1000 bootstrap samples.

The associations between the dietary patterns (response variables) and age (50-55, 56-60, 61-65, 66-69 years), smoking (never, former, current), BMI (<18.5, 18.5-24.9, $25 \cdot 0-29 \cdot 9, \quad \geq 30 \cdot 0 \mathrm{~kg} / \mathrm{m}^{2}$ ), education (primary school, secondary school, upper secondary school, academy/ college/university $\leq 4$ years and $>4$ years) and physical activity (quartiles, MET-h/week) were studied by multiple linear regression analyses. All variables were adjusted for each other and for energy intake. We analysed trends across categories of a variable by assigning equally spaced values (e.g. 1, 2, 3 or 4) to the categories and treating the variable as a continuous variable in the regression analysis. Regression coefficients $(\beta)$ with $95 \%$ confidence intervals are presented.

All tests were two-sided and $P<0.05$ was considered statistically significant. The analyses were conducted using the statistical software package IBM SPSS Statistics Version 20.0.

\section{Results}

The mean age of the 6298 women was 57.9 years (range 50-69 years) and 69\% were aged 50-60 years. Twenty per cent had no education or had only completed primary school. Twenty-one per cent were not doing any physical activity or only light physical activity, with a mean MET-h/week of 6.7 (range 0-17.5). Further, $49 \%$ had a BMI of $\geq 25.0 \mathrm{~kg} / \mathrm{m}^{2}, 45 \%$ had never smoked and $50 \%$ had an alcohol intake of $\leq 4.8 \mathrm{~g} / \mathrm{d}$.

\section{Dietary patterns}

We identified three major dietary patterns, all with eigenvalues $\geq 2 \cdot 0$. The interpretation of the components and the point of inflexion on the curve in the scree plot justified retaining three components, which accounted for $17.5 \%$ of the total variance. Table 1 presents the three dietary patterns, where factor loadings with absolute values of $\geq 0.3$ are indicated in bold. The first dietary pattern was labelled 'Prudent' and was characterized by high positive loadings for vegetables, fruits, fish as dinner, herbs and spices, berries, nuts and seeds, legumes, meat dishes, vegetarian food, soup, tea, salad dressings and poultry. The second dietary pattern was labelled 'Western' and was characterized by high loadings for potatoes, sauce, refined grains, processed meat, cakes and desserts, margarine, sweet spreads, red meat and game, and high negative loadings for wine, nuts and seeds, and herbs and spices. The third pattern was labelled 'Continental' and was characterized by high loadings for tomato sauce, pasta, processed meat, fat-rich potatoes, pizza, salty snacks, salad dressings, rice, poultry, mustard and wine.

\section{Intakes of energy and nutrients}

The correlations between dietary pattern scores and daily intakes of selected macro- and micronutrients are presented in Table 2. All correlation coefficients presented in this section were statistically significant $(P<0 \cdot 05)$. For all three dietary patterns there was a positive association with energy intake, the associations being strongest for the 'Prudent' and 'Western' patterns.

The 'Prudent' pattern was positively associated with protein, fibre, vitamin $\mathrm{D}$, vitamin $\mathrm{B}_{12}, \mathrm{Ca}, \mathrm{Fe}$ and $\mathrm{Mg}$ $(0 \cdot 12 \leq r \leq 0 \cdot 74)$, and inversely associated with saturated fat, carbohydrate and sugar $(-0 \cdot 24 \leq r \leq-0 \cdot 13)$. An increasing score for the 'Western' pattern was associated with increasing intakes of total fat, saturated fat, carbohydrate, sugar, vitamin $\mathrm{B}_{12}$, $\mathrm{Ca}$ and $\mathrm{Mg}(0 \cdot 13 \leq r \leq 0 \cdot 36)$, 
Table 1 Factor loadings ${ }^{\star}$ for the three dietary patterns found by principal component analysis among 6298 women aged 50-69 years, Norwegian Breast Cancer Screening Programme, 2008

\begin{tabular}{|c|c|c|c|}
\hline \multirow[b]{2}{*}{ Food group } & \multicolumn{3}{|c|}{ Dietary pattern } \\
\hline & 'Prudent' & 'Western' & 'Continental' \\
\hline Vegetables & 0.65 & -0.05 & 0.03 \\
\hline Fruits & 0.52 & 0.02 & -0.20 \\
\hline Fish, dinner & 0.52 & 0.18 & -0.08 \\
\hline Herbs and spices & 0.50 & -0.30 & 0.19 \\
\hline Berries & 0.48 & 0.18 & -0.17 \\
\hline Nuts and seeds & 0.47 & -0.30 & 0.20 \\
\hline Legumes & 0.40 & -0.23 & 0.06 \\
\hline Meat dishes & 0.40 & 0.22 & 0.17 \\
\hline Vegetarian food & 0.32 & -0.22 & 0.004 \\
\hline Soup & 0.30 & 0.12 & 0.10 \\
\hline Tea & 0.30 & -0.16 & 0.004 \\
\hline Whole grains & 0.26 & 0.26 & -0.19 \\
\hline Egg & 0.23 & -0.02 & 0.13 \\
\hline Fish, bread spread & 0.22 & 0.13 & -0.03 \\
\hline Water & 0.21 & -0.05 & -0.01 \\
\hline Fruit juice & 0.13 & 0.05 & 0.02 \\
\hline Potatoes & -0.02 & 0.59 & -0.12 \\
\hline Sauce & -0.05 & 0.57 & 0.23 \\
\hline Refined grains & -0.04 & 0.54 & 0.05 \\
\hline Processed meat & -0.02 & 0.47 & 0.44 \\
\hline Cakes and desserts & 0.09 & 0.46 & 0.15 \\
\hline Margarine & -0.10 & 0.41 & 0.06 \\
\hline Sweet spreads & 0.06 & 0.38 & -0.17 \\
\hline Red meat and game & $0 \cdot 11$ & 0.37 & 0.28 \\
\hline Wine & 0.09 & -0.32 & 0.31 \\
\hline Cheese & 0.08 & 0.25 & 0.03 \\
\hline Mayonnaise & 0.02 & 0.24 & 0.15 \\
\hline Coffee & -0.10 & 0.23 & 0.07 \\
\hline Sugar-sweetened beverages & $-0 \cdot 10$ & 0.23 & -0.01 \\
\hline Butter & -0.01 & 0.17 & 0.03 \\
\hline Sugar & -0.001 & 0.14 & 0.01 \\
\hline Tomato sauce & 0.22 & $0 \cdot 10$ & 0.53 \\
\hline Pasta & 0.12 & -0.04 & 0.51 \\
\hline Fat-rich potatoes & 0.03 & 0.22 & 0.39 \\
\hline Pizza & -0.05 & 0.14 & 0.38 \\
\hline Salty snacks & -0.08 & 0.12 & 0.38 \\
\hline Salad dressings & 0.36 & -0.14 & 0.37 \\
\hline Rice & 0.20 & -0.04 & 0.36 \\
\hline Poultry & 0.33 & -0.14 & 0.35 \\
\hline Mustard & 0.15 & 0.07 & 0.33 \\
\hline Sweets & 0.02 & 0.13 & 0.29 \\
\hline Soya sauce & 0.25 & -0.16 & 0.28 \\
\hline Barbecue and taco seasoning & 0.06 & 0.08 & 0.25 \\
\hline Low-fat dairy products & 0.07 & 0.12 & -0.24 \\
\hline Beer & 0.04 & -0.03 & 0.21 \\
\hline High-fat dairy products & 0.03 & 0.17 & $-0 \cdot 19$ \\
\hline Sweeteners & -0.03 & 0.05 & 0.19 \\
\hline $\begin{array}{l}\text { Artificially sweetened } \\
\text { beverages }\end{array}$ & -0.06 & 0.02 & $0 \cdot 16$ \\
\hline Liquor & -0.05 & 0.02 & 0.14 \\
\hline Total variance explained (\%) & $6 \cdot 1$ & $6 \cdot 0$ & $5 \cdot 4$ \\
\hline
\end{tabular}

${ }^{*}$ Factor loadings between -0.30 and 0.30 are indicated in bold font.

and decreasing intakes of alcohol, protein and fibre $(-0.37 \leq r \leq-0 \cdot 17)$. However, the positive correlations between the 'Western' pattern and vitamin $\mathrm{B}_{12}$ and $\mathrm{Mg}$ were much lower than the correlations observed between these two nutrients and the 'Prudent' pattern. An increasing score for the 'Continental' pattern was associated with increasing intakes of alcohol, total fat and saturated fat $(0.22 \leq r \leq 0.31)$, and decreasing intakes of carbohydrate, fibre and $\mathrm{Ca}(-0 \cdot 36 \leq r \leq-0 \cdot 14)$.

\section{Characteristics of the study sample}

Table 3 presents the general characteristics of the study sample across quartiles of dietary pattern scores. Women in the highest quartile of the 'Prudent' pattern were higher educated, more physically active, less likely to smoke, had a slightly higher alcohol intake and were more likely to use dietary supplements than the women in the lowest quartile. Women with the highest scores for the 'Western' pattern were lower educated, less physically active, had a lower alcohol intake and were more likely to smoke than those with the lowest scores. Women in the highest quartile of the 'Continental' pattern were younger, higher educated, more likely to smoke, had a higher alcohol intake and were less likely to use supplements than those in the lowest quartile.

\section{Associations between dietary patterns, demographic and lifestyle factors}

Adjusted regression coefficients for each dietary pattern according to age, education, BMI physical activity and smoking are presented in Table 4. An increasing score for the 'Prudent' pattern was strongly positively associated with age, education, BMI and physical activity $\left(P_{\text {trend }}<\right.$ $0 \cdot 001)$, and current smokers had lower scores than never smokers $(P<0 \cdot 001)$. For the 'Western' pattern we found a strong positive trend for age and BMI (0.001 $\leq P_{\text {trend }} \leq$ 0.006), a strong inverse trend for education and physical activity $\left(P_{\text {trend }}<0.001\right)$, and a weaker association with current smoking than for the 'Prudent' pattern $(P<0 \cdot 001)$. For the 'Continental' pattern there was a strong inverse trend for age and physical activity $\left(P_{\text {trend }}<0.001\right)$, a strong positive trend for education $\left(P_{\text {trend }}<0.001\right)$, and both former and current smokers had higher scores than never smokers $(P<0 \cdot 001)$.

\section{Discussion}

We identified three distinct dietary patterns in a large group of middle-aged Norwegian women: 'Prudent', 'Western' and 'Continental', which accounted for $17.5 \%$ of the total variance. The 'Prudent' pattern was positively associated with a healthy lifestyle (physically active, being a non-smoker and having a low alcohol intake), age and education. The 'Western' pattern was inversely associated with indicators of a healthy lifestyle (physically active and being a non-smoker), education and positively associated with age. The 'Continental' pattern was inversely associated with a healthy lifestyle and age, and positively associated with education.

There are some similarities between the dietary patterns discerned in the present study and those found in other studies. Although the methodological choices of the studies may influence the factor solutions, i.e. which food groups or food items characterize each factor ${ }^{(8)}$, two dietary patterns have emerged repeatedly across countries: one characterized by high vegetable and fruit intakes 
Table 2 Pearson correlation coefficients $(r)$ with $95 \%$ confidence intervals* between dietary pattern scores and daily intakes of selected macro- and micronutrients among 6298 women aged 50-69 years, Norwegian Breast Cancer Screening Programme, 2008

\begin{tabular}{|c|c|c|c|c|c|c|}
\hline \multirow[b]{3}{*}{ Nutrient } & \multicolumn{6}{|c|}{ Dietary pattern } \\
\hline & \multicolumn{2}{|c|}{ 'Prudent' } & \multicolumn{2}{|c|}{ 'Western' } & \multicolumn{2}{|c|}{ 'Continental' } \\
\hline & $r$ & $95 \% \mathrm{Cl}$ & $r$ & $95 \% \mathrm{Cl}$ & $r$ & $95 \% \mathrm{Cl}$ \\
\hline Energy $(\mathrm{kJ} / \mathrm{d})$ & 0.59 & $0.58,0.61$ & 0.54 & $0.52,0.57$ & $0 \cdot 16$ & $0.14,0.19$ \\
\hline Alcohol $(\mathrm{g} / \mathrm{d})$ & 0.07 & $0.04,0.10$ & -0.28 & $-0.30,-0.25$ & 0.36 & $0.34,0.39$ \\
\hline Alcohol (E\%) & -0.06 & $-0.09,-0.04$ & -0.37 & $-0.39,-0.35$ & 0.31 & $0.29,0.33$ \\
\hline Total fat (E\%) & 0.06 & $0.03,0.08$ & 0.19 & $0.16,0.22$ & 0.30 & $0.28,0.32$ \\
\hline Saturated fat (E\%) & -0.24 & $-0.26,-0.21$ & 0.36 & $0.33,0.38$ & 0.22 & $0.19,0.24$ \\
\hline Protein (E\%) & 0.16 & $0 \cdot 13,0.18$ & -0.17 & $-0.19,-0.14$ & -0.09 & $-0.11,-0.06$ \\
\hline Carbohydrate (E\%) & -0.13 & $-0 \cdot 16,-0 \cdot 10$ & 0.13 & $0 \cdot 10,0.16$ & -0.36 & $-0.38,-0.34$ \\
\hline Added sugar (E\%) & -0.18 & $-0.21,-0.16$ & 0.30 & $0.28,0.32$ & -0.05 & $-0.07,-0.02$ \\
\hline Fibre $(E \%)$ & 0.40 & $0.37,0.42$ & -0.30 & $-0.32,-0.27$ & -0.26 & $-0.29,-0.24$ \\
\hline Vitamin D $(\mu \mathrm{g} / \mathrm{d})$ & 0.27 & $0.25,0.30$ & 0.06 & $0.03,0.08$ & -0.07 & $-0.09,-0.04$ \\
\hline Vitamin $B_{12}(\mu \mathrm{g} / \mathrm{d})$ & 0.45 & $0.43,0.48$ & 0.30 & $0.27,0.32$ & -0.01 & $-0.04,0.01$ \\
\hline $\mathrm{Ca}(\mathrm{mg} / \mathrm{d})$ & 0.32 & $0.30,0.34$ & 0.27 & $0.24,0.29$ & -0.14 & $-0.17,-0.12$ \\
\hline $\mathrm{Fe}(\mathrm{mg} / \mathrm{d})$ & $0 \cdot 12$ & $0.10,0.15$ & 0.02 & $-0.004,0.04$ & 0.01 & $-0.02,0.03$ \\
\hline $\mathrm{Mg}(\mathrm{mg} / \mathrm{d})$ & 0.74 & $0.72,0.75$ & 0.27 & $0.25,0.30$ & 0.01 & $-0.02,0.03$ \\
\hline
\end{tabular}

$\mathrm{E} \%$, percentage of energy intake.

${ }^{*}$ Confidence intervals based on 1000 bootstrap samples.

Table 3 Participant characteristics across quartiles $(Q)$ of dietary pattern scores among 6298 women aged 50-69 years, Norwegian Breast Cancer Screening Programme, 2008

\begin{tabular}{|c|c|c|c|c|c|c|c|c|c|c|c|c|}
\hline \multirow[b]{3}{*}{ Characteristic } & \multicolumn{12}{|c|}{ Dietary pattern } \\
\hline & \multicolumn{4}{|c|}{ 'Prudent' } & \multicolumn{4}{|c|}{ 'Western' } & \multicolumn{4}{|c|}{ 'Continental' } \\
\hline & Q1 & Q2 & Q3 & Q4 & Q1 & Q2 & Q3 & Q4 & Q1 & Q2 & Q3 & Q4 \\
\hline$n$ & 1574 & 1575 & 1575 & 1574 & 1574 & 1575 & 1575 & 1574 & 1574 & 1575 & 1575 & 1574 \\
\hline Age (years, mean) & $57 \cdot 2$ & 57.4 & 57.8 & $57 \cdot 8$ & $57 \cdot 1$ & 57.7 & 57.9 & $57 \cdot 6$ & $59 \cdot 3$ & $58 \cdot 3$ & $57 \cdot 1$ & 55.8 \\
\hline \multicolumn{13}{|l|}{ Education (\%) } \\
\hline Primary and secondary school & 24.7 & $20 \cdot 1$ & $19 \cdot 4$ & $15 \cdot 4$ & 13.5 & $18 \cdot 7$ & $22 \cdot 0$ & $25 \cdot 4$ & $26 \cdot 2$ & 18.5 & $19 \cdot 6$ & $15 \cdot 3$ \\
\hline Upper secondary school & $43 \cdot 1$ & $40 \cdot 3$ & 39.9 & $36 \cdot 1$ & $34 \cdot 2$ & $39 \cdot 0$ & $41 \cdot 4$ & $44 \cdot 8$ & $38 \cdot 2$ & $41 \cdot 8$ & 39.9 & 39.5 \\
\hline $\begin{array}{l}\text { Academy/college/university } \\
\text { ( } \leq 4 \text { years) }\end{array}$ & $20 \cdot 8$ & $24 \cdot 9$ & $23 \cdot 4$ & $28 \cdot 5$ & $28 \cdot 1$ & $25 \cdot 4$ & $23 \cdot 6$ & $20 \cdot 5$ & $22 \cdot 4$ & $23 \cdot 6$ & $24 \cdot 1$ & $27 \cdot 4$ \\
\hline $\begin{array}{l}\text { Academy/college/university } \\
\text { (>4 years) }\end{array}$ & 11.4 & $14 \cdot 7$ & $17 \cdot 3$ & $20 \cdot 0$ & $24 \cdot 2$ & $16 \cdot 9$ & $13 \cdot 1$ & $9 \cdot 3$ & $13 \cdot 2$ & $16 \cdot 1$ & $16 \cdot 4$ & $17 \cdot 8$ \\
\hline Light & $126 \cdot 6$ & $151 \cdot 6$ & 173.9 & $191 \cdot 7$ & $167 \cdot 1$ & $168 \cdot 3$ & $157 \cdot 6$ & $155 \cdot 2$ & $170 \cdot 6$ & $159 \cdot 5$ & $164 \cdot 0$ & 154.9 \\
\hline Moderate & 68.6 & 84.0 & $97 \cdot 7$ & $118 \cdot 1$ & $102 \cdot 3$ & $96 \cdot 3$ & 87.4 & $86 \cdot 2$ & 107.5 & 91.8 & $87 \cdot 6$ & 86.6 \\
\hline Strenuous & 29.9 & $38 \cdot 7$ & $46 \cdot 6$ & $59 \cdot 8$ & $56 \cdot 1$ & $46 \cdot 0$ & $38 \cdot 2$ & $37 \cdot 4$ & $45 \cdot 1$ & 43.5 & 42.5 & $45 \cdot 7$ \\
\hline $\begin{array}{l}\text { Physical activity level (MET-h/week, } \\
\text { mean) }\end{array}$ & $13 \cdot 8$ & $17 \cdot 1$ & $20 \cdot 0$ & 23.8 & $21 \cdot 3$ & $19 \cdot 6$ & $17 \cdot 5$ & $17 \cdot 2$ & $20 \cdot 3$ & $18 \cdot 6$ & $18 \cdot 3$ & $18 \cdot 3$ \\
\hline Smoking (\%) & 27.5 & $18 \cdot 8$ & $16 \cdot 3$ & 14.9 & $17 \cdot 2$ & $16 \cdot 8$ & $19 \cdot 7$ & 23.8 & $15 \cdot 5$ & $17 \cdot 0$ & $20 \cdot 4$ & $24 \cdot 6$ \\
\hline Alcohol (g/d, mean) & $7 \cdot 0$ & $7 \cdot 7$ & $7 \cdot 7$ & 8.7 & $11 \cdot 6$ & $8 \cdot 1$ & 6.5 & $5 \cdot 2$ & 3.7 & $6 \cdot 1$ & $9 \cdot 0$ & 11.7 \\
\hline Supplement user (\%)* & $75 \cdot 2$ & 82.9 & $85 \cdot 1$ & 88.2 & 83.4 & 84.3 & 83.6 & $80 \cdot 1$ & $86 \cdot 1$ & 83.0 & 82.9 & $79 \cdot 2$ \\
\hline
\end{tabular}

MET, metabolic equivalent of task.

*Data missing for 118 women.

and one characterized by high meat and starch intakes $^{(23-29)}$, frequently called a 'Prudent' and a 'Western' dietary pattern, respectively. In a study investigating the reproducibility and validity of dietary patterns, Hu et al. ${ }^{\text {(30) }}$ found the 'Prudent' and the 'Western' patterns to be relatively stable over time. Although the 'Prudent' and the 'Western' patterns often are characterized by some typical food groups, they may also contain food groups differing between populations due to cultural differences and to subjective decisions by the investigators, thereby making comparisons between studies challenging. Also in the present study a 'Prudent' and a 'Western' pattern emerged. Our 'Western' pattern shared some similarities with the 'Bread and potatoes' pattern found in a Scandinavian study $^{(31)}$, both comprised of potatoes, white bread (fine grains in our pattern), processed meat, margarine, sweet spreads and cakes. Further, our 'Prudent' pattern corresponds to the 'Prudent' pattern found in a Norwegian study where both were characterized by vegetables, fruits, fish, legumes and salad dressings ${ }^{(32)}$. 
Table 4 Adjusted* estimated regression coefficients $(\beta)$ with $95 \%$ confidence intervals for dietary patterns in relation to age, education and lifestyle factors among 6298 women aged 50-69 years, Norwegian Breast Cancer Screening Programme, 2008

\begin{tabular}{|c|c|c|c|c|c|c|c|}
\hline \multirow[b]{3}{*}{ Characteristic } & \multirow[b]{3}{*}{$n$} & \multicolumn{6}{|c|}{ Dietary pattern } \\
\hline & & \multicolumn{2}{|c|}{ 'Prudent' } & \multicolumn{2}{|c|}{ 'Western' } & \multicolumn{2}{|c|}{ 'Continental' } \\
\hline & & $\beta$ & $95 \% \mathrm{Cl}$ & $\beta$ & $95 \% \mathrm{Cl}$ & $\beta$ & $95 \% \mathrm{Cl}$ \\
\hline \multicolumn{8}{|l|}{ Age (years) } \\
\hline $50-55$ & 2327 & Ref. & _ & Ref. & _- & Ref. & - \\
\hline $56-60$ & 1995 & 0.17 & $0.12,0.21$ & 0.01 & $-0.04,0.06$ & -0.36 & $-0.42,-0.31$ \\
\hline $61-65$ & 1677 & 0.21 & $0.16,0.26$ & 0.06 & $0.01,0.11$ & -0.62 & $-0.68,-0.56$ \\
\hline $66-69$ & 299 & 0.22 & $0.13,0.32$ & $0 \cdot 10$ & $0.003,0.20$ & -0.81 & $-0.92,-0.70$ \\
\hline$P_{\text {trend }}$ & & $<0.001$ & & 0.006 & & $<0.001$ & \\
\hline \multicolumn{8}{|l|}{ Education } \\
\hline Primary and secondary school & 1253 & Ref. & - & Ref. & - & Ref. & - \\
\hline Upper secondary school & 2510 & 0.05 & $-0.005,0.10$ & -0.07 & $-0.12,-0.02$ & 0.11 & $0.05,0.18$ \\
\hline Academy/college/university ( $\leq 4$ years) & 1536 & $0 \cdot 16$ & $0.10,0.22$ & -0.31 & $-0.37,-0.25$ & 0.22 & $0.14,0.29$ \\
\hline Academy/college/university ( $>4$ years) & 999 & 0.29 & $0.22,0.35$ & -0.51 & $-0.58,-0.44$ & 0.24 & $0.16,0.32$ \\
\hline$P_{\text {trend }}$ & & $<0.001$ & & $<0.001$ & & $<0.001$ & \\
\hline \multicolumn{8}{|l|}{$\mathrm{BMI}\left(\mathrm{kg} / \mathrm{m}^{2}\right)$} \\
\hline $18.5-24.9$ & 3183 & Ref. & - & Ref. & - & Ref. & \\
\hline $25 \cdot 0-29 \cdot 9$ & 2232 & 0.07 & $0.03,0.12$ & 0.05 & $0.01,0.10$ & 0.08 & $0.03,0.13$ \\
\hline$\geq 30 \cdot 0$ & 827 & 0.12 & $0.06,0.18$ & 0.12 & $0.06,0.19$ & 0.13 & $0.06,0.20$ \\
\hline $\bar{P}_{\text {trend }}{ }^{-}$ & & $<0.001$ & & 0.001 & & $<0.001$ & \\
\hline$<18.5$ & 56 & 0.01 & $-0.19,0.21$ & 0.11 & $-0.10,0.32$ & -0.22 & $-0.46,0.03$ \\
\hline \multicolumn{8}{|l|}{ Physical activity (MET-h/week) } \\
\hline Quartile $1(0-7.2)$ & 1450 & Ref. & - & Ref. & - & Ref. & - \\
\hline Quartile $2(7.5-14.3)$ & 1720 & 0.12 & $0.06,0.17$ & -0.09 & $-0.15,-0.04$ & -0.04 & $-0.11,0.02$ \\
\hline Quartile $3(14.4-24.0)$ & 1540 & 0.27 & $0.21,0.32$ & -0.28 & $-0.34,-0.23$ & -0.04 & $-0.11,0.03$ \\
\hline Quartile $4(24.1-101.5)$ & 1588 & 0.46 & $0.40,0.52$ & -0.40 & $-0.46,-0.34$ & -0.14 & $-0.21,-0.07$ \\
\hline$P_{\text {trend }}$ & & $<0.001$ & & $<0.001$ & & $<0.001$ & \\
\hline \multicolumn{8}{|l|}{ Smoking } \\
\hline Never & 2828 & Ref. & - & Ref. & - & Ref. & - \\
\hline Former & 2250 & 0.04 & $-0.005,0.08$ & -0.16 & $-0.20,-0.11$ & 0.29 & $0.24,0.35$ \\
\hline Current & 1220 & -0.14 & $-0.20,-0.09$ & 0.04 & $-0.01,0.10$ & 0.34 & $0.28,0.40$ \\
\hline$P$ & & $<0.001$ & & $<0.001$ & & $<0.001$ & \\
\hline
\end{tabular}

MET, metabolic equivalent of task; Ref., reference category.

${ }^{*}$ All characteristics are mutually adjusted for each other and for energy intake.

$\dagger \mathrm{BMI}$ category ' $<18.5$ ' is not included in the test for trend.

Due to the unique dietary culture in every country additional dietary patterns have recurrently been identified. During the last decades Norwegians' eating and drinking habits have changed towards more continental habits, which are related to a general increase in the standard of living and more travelling abroad ${ }^{(33)}$. The 'Continental' pattern reflects these changes, both in regard to the food groups and the positive association between this pattern and alcohol intake. In an older study among middle-aged Norwegian women (41-56 years) on dietary patterns and lifestyle factors ${ }^{(34)}$, one dietary pattern had high loadings for rice, pasta, red meat and meat products, pizza, chocolate and salty snacks, which is similar to our 'Continental' pattern. Furthermore, in the Australian Longitudinal Study on Women's Health among young (25-30 years) and middle-aged (50-55 years) women, one of the six dietary patterns was characterized as a 'Processed meat, meat and takeaway' pattern and partly corresponds with our 'Continental' pattern by the food groups processed meat, red meat, fat-rich potatoes, pizza and chicken ${ }^{(35)}$. Also a Danish study on dietary patterns and associated healthrelated lifestyle factors among men and women (18-75 years) found a similar 'Fast food' pattern ${ }^{(28)}$. Since similar dietary patterns to the three patterns found in the present study have been observed in other populations, we assume that they may reflect true underlying patterns and were not a result of chance observations. In a sub-sample of the women from the present study sample ( $n$ 361) we used carotenoids in plasma as biomarkers for fruit and vegetable intake as a means of validating the dietary patterns, and concluded that the dietary patterns were meaningful ${ }^{(36)}$.

The three dietary patterns retained from the PCA accounted for $17.5 \%$ of the total variance. This is consistent with the results of other studies using comparable methods, where the explained variance was 16.3-18.5\% for three dietary patterns ${ }^{(37,38)}$. In most studies the dietary patterns represent a limited extent of variance (13-30\%) in dietary data ${ }^{(39)}$. The total variance explained by the dietary patterns depends on the number of variables included in the analysis. We had forty-nine food groups as input variables to the PCA. With even more aggregation of the food groups, it is likely that we would have accounted for a higher proportion of the variance but the level of detail would be reduced, which was undesirable.

We found positive associations between the healthy 'Prudent' pattern and protein, fibre and all micronutrients, 
and inverse associations with saturated fat, carbohydrate and sugar. Generally, this type of plant-food dominated dietary pattern also provides a number of antioxidants, phenolic compounds and phyto-oestrogens that have been associated with protection against many chronic diseases $^{(40)}$. The women with high adherence to the 'Prudent' pattern comply with the Norwegian and Nordic nutrition recommendations ${ }^{(40)}$. High 'Western' pattern scores were associated with higher intakes of total fat, saturated fat, carbohydrates and sugar, and lower intakes of protein and fibre, which are characteristics of an unhealthy diet. However, this pattern was also associated with a decreased intake of alcohol and increased intakes of vitamin $\mathrm{B}_{12}, \mathrm{Ca}$ and $\mathrm{Mg}$. $\mathrm{A}$ high adherence to the 'Continental' pattern was associated with higher intakes of alcohol, total fat and saturated fat and lower intakes of fibre and $\mathrm{Ca}$, which classifies this pattern also as an unhealthy pattern.

The associations observed between dietary patterns and physical activity and smoking were in the expected directions (Table 3), suggestive of a healthy behaviour of women scoring high on the 'Prudent' pattern and an unhealthy behaviour of women scoring high on the 'Western' and 'Continental' patterns. Higher scores for the 'Prudent' pattern were also associated with higher education, whereas higher scores for the 'Western' pattern were associated with lower education. This is in accordance with previous findings ${ }^{(28,35,41,42)}$. Interestingly, a higher score for the unhealthy 'Continental' pattern was associated with a higher education. These women had also higher daily alcohol intake than those with higher scores for the other two patterns, with wine as the main source. A higher education is associated with a higher income, i.e. a higher socio-economic position, and previous studies have found a positive association between higher socio-economic position and alcohol consumption ${ }^{(43-45)}$. Furthermore, women with high adherence to the 'Continental' pattern were younger and more likely to smoke. An increasing inverse association with age was also found in the Danish study for its corresponding 'Fast food' pattern ${ }^{(28)}$. Further, the Australian study reported an inverse association between its 'Processed meat, meat and takeaway' pattern and age ${ }^{(35)}$. It seems as if patterns comparable to our 'Continental' pattern are preferred by the younger part of the population.

In our study all of the dietary patterns had a positive association with BMI. The positive association between the 'Prudent' pattern and BMI may indicate that overweight women adopt a healthy diet to lose weight. Another explanation could be a general under-reporting of foods, or over-reporting of foods considered 'healthy' and under-reporting of foods considered 'unhealthy', related to social desirability, among those with a higher $\mathrm{BMI}^{(46-48)}$.

The strengths of our study include the extensive information on diet and lifestyle and the large study sample from different parts of the country.
The present study holds some limitations. First, there are several inherent limitations of a cross-sectional design ${ }^{(49)}$, one of the major limitations being the possibility of reverse causation. Further, the FFQ had an extra focus on fruit, vegetables and antioxidant-rich foods and beverages, and therefore these food items may have been overestimated. Self-reported dietary intake data introduce measurement errors ${ }^{(50,51)}$ that could distort the composition of the food groups in a dietary pattern and may have made it more difficult to discern distinctive patterns. Many subjective decisions are made when assessing dietary patterns that can impact the number and type of dietary patterns derived $^{(7,8,52,53)}$. However, to test the robustness of our results we did a sensitivity analysis by randomly splitting the data set in two halves and conducting the PCA in these samples. The same components were extracted from these samples with only minor differences in factor loadings. The self-reported height and weight might also lead to measurement errors that could have biased the associations between the dietary patterns and BMI in our study.

\section{Conclusion}

In conclusion, in this large sample of Norwegian women aged 50-69 years we identified three dietary patterns: 'Prudent', 'Western' and 'Continental'. Our findings suggest that adherence to a 'Prudent' dietary pattern is associated with a generally healthy lifestyle, while adherence to a 'Western' or a 'Continental' dietary pattern is associated with a generally unhealthy lifestyle. Keeping ageing women healthy, fit and active can reduce the costs of long-term care for chronic conditions. There is a need to form effective strategies on ways to modify unhealthy food habits and lifestyles to prevent morbidity and premature mortality from NCD.

\section{Supplementary material}

To view supplementary material for this article, please visit http://dx.doi.org/10.1017/S1368980015003547

\section{Acknowledgements}

Financial support: This project was supported by the Research Council of Norway (G.U., grant number 196999). The Research Council of Norway had no role in the design, analysis or writing of this article. Conflict of interest: None of the authors have any financial or other interests concerning the outcomes of the investigation or any conflicts of interest to declare. Authorship: M.S.M. conducted the nutritional and statistical analyses and wrote the paper; M.B.V. contributed to the statistical analysis, the interpretation of the results and the development and revision of the manuscript; A.L.K. contributed to analysing the data and revision of the manuscript; G.U. designed and conducted the research, 
contributed to the interpretation of the results and the development and revision of the manuscript; L.F.A. contributed to the interpretation of the results, the development and revision of the manuscript and had primary responsibility for final content. All authors read and approved the final manuscript. Ethics of buman subject participation: This study was conducted according to the guidelines laid down in the Declaration of Helsinki and all procedures involving human subjects were approved by the regional ethics committee and the Norwegian Data Protection Authority. Written informed consent was obtained from all subjects.

\section{References}

1. World Health Organization (2002) Women and the Rapid Rise of Noncommunicable Diseases. Geneva: WHO.

2. Alwan A (2011) Global Status Report on Noncommunicable Diseases 2010. Geneva: WHO.

3. Fifty-seventh World Health Assembly (2004) WHA 57.17. Global Strategy on Diet and Physical Activity. Geneva: WHO.

4. EFSA Panel on Dietetic Products, Nutrition and Allergies (2010) Scientific Opinion on Establishing Food-Based Dietary Guidelines. Parma: EFSA.

5. Jacobs DR Jr, Gross MD \& Tapsell LC (2009) Food synergy: an operational concept for understanding nutrition. $A m J$ Clin Nutr 89, issue 5, 1543S-1548S.

6. Michels KB \& Schulze MB (2005) Can dietary patterns help us detect diet-disease associations? Nutr Res Rev $\mathbf{1 8}$, 241-248.

7. Hu FB (2002) Dietary pattern analysis: a new direction in nutritional epidemiology. Curr Opin Lipidol 13, 3-9.

8. Newby PK \& Tucker KL (2004) Empirically derived eating patterns using factor or cluster analysis: a review. Nutr Rev 62, 177-203

9. Moeller SM, Reedy J, Millen AE et al. (2007) Dietary patterns: challenges and opportunities in dietary patterns research an Experimental Biology workshop, April 1, 2006. J Am Diet Assoc 107, 1233-1239.

10. Harlow SD, Gass M, Hall JE et al. STRAW 10 Collaborative Group (2012) Executive summary of the Stages of Reproductive Aging Workshop + 10: addressing the unfinished agenda of staging reproductive aging. J Clin Endocrinol Metab 97, 1159-1168.

11. Melby MK, Sievert LL, Anderson D et al. (2011) Overview of methods used in cross-cultural comparisons of menopausal symptoms and their determinants: guidelines for Strengthening the Reporting of Menopause and Aging (STROMA) studies. Maturitas 70, 99-109.

12. Hofvind SS, Wang H \& Thoresen S (2003) The Norwegian Breast Cancer Screening Program: re-attendance related to the women's experiences, intentions and previous screening result. Cancer Causes Control 14, 391-398.

13. Hofvind S, Geller B, Vacek PM et al. (2007) Using the European guidelines to evaluate the Norwegian Breast Cancer Screening Program. Eur J Epidemiol 22, 447-455.

14. Andersen LF, Solvoll K, Johansson LR et al. (1999) Evaluation of a food frequency questionnaire with weighed records, fatty acids, and $\alpha$-tocopherol in adipose tissue and serum. Am J Epidemiol 150, 75-87.

15. Carlsen MH, Lillegaard IT, Karlsen A et al. (2010) Evaluation of energy and dietary intake estimates from a food frequency questionnaire using independent energy expenditure measurement and weighed food records. Nutr J 9, 37.
16. Hustvedt BE, Christophersen A, Johnsen LR et al. (2004) Description and validation of the ActiReg: a novel instrument to measure physical activity and energy expenditure. Br J Nutr 92, 1001-1008.

17. Carlsen MH, Karlsen A, Lillegaard IT et al. (2011) Relative validity of fruit and vegetable intake estimated from an FFQ, using carotenoid and flavonoid biomarkers and the method of triads. Br J Nutr 105, 1530-1538.

18. Qureshi SA, Ellingjord-Dale M, Hofvind S et al. (2012) Physical activity and mammographic density in a cohort of postmenopausal Norwegian women; a cross-sectional study. Springerplus 1, 75.

19. Dallal CM, Sullivan-Halley J, Ross RK et al. (2007) Long-term recreational physical activity and risk of invasive and in situ breast cancer: the California teachers study. Arch Intern Med 167, 408-415.

20. Ainsworth BE, Haskell WL, Whitt MC et al. (2000) Compendium of physical activities: an update of activity codes and MET intensities. Med Sci Sports Exerc 32, 9 Suppl., S498-S504.

21. Tabachnick BG \& Fidell LS (2007) Using Multivariate Statistics, 5th ed. Boston, MA: Pearson Education Publications.

22. Hutcheson G \& Sofroniou N (1999) The Multivariate Social Scientist. London: SAGE.

23. Flood A, Rastogi T, Wirfalt E et al. (2008) Dietary patterns as identified by factor analysis and colorectal cancer among middle-aged Americans. Am J Clin Nutr 88, 176-184.

24. Sanchez-Villegas A, Delgado-Rodriguez M, MartinezGonzalez MA et al. (2003) Gender, age, sociodemographic and lifestyle factors associated with major dietary patterns in the Spanish Project SUN (Seguimiento Universidad de Navarra). Eur J Clin Nutr 57, 285-292.

25. Chocano-Bedoya PO, O'Reilly EJ, Lucas M et al. (2013) Prospective study on long-term dietary patterns and incident depression in middle-aged and older women. Am J Clin Nutr 98, 813-820.

26. Kim MK, Sasaki S, Otani T et al. (2005) Dietary patterns and subsequent colorectal cancer risk by subsite: a prospective cohort study. Int I Cancer 115, 790-798.

27. Terry P, Hu FB, Hansen $\mathrm{H}$ et al. (2001) Prospective study of major dietary patterns and colorectal cancer risk in women. Am J Epidemiol 154, 1143-1149.

28. Knudsen VK, Matthiessen J, Biltoft-Jensen A et al. (2014) Identifying dietary patterns and associated health-related lifestyle factors in the adult Danish population. Eur J Clin Nutr 68, 736-740.

29. Konstantinova SV, Tell GS, Vollset SE et al. (2008) Dietary patterns, food groups, and nutrients as predictors of plasma choline and betaine in middle-aged and elderly men and women. Am J Clin Nutr 88, 1663-1669.

30. Hu FB, Rimm E, Smith-Warner SA et al. (1999) Reproducibility and validity of dietary patterns assessed with a food-frequency questionnaire. Am J Clin Nutr 69, 243-249.

31. Engeset D, Hofoss D, Nilsson LM et al. (2015) Dietary patterns and whole grain cereals in the Scandinavian countries - differences and similarities. The HELGA project. Public Health Nutr 18, 905-915.

32. Raberg Kjollesdal MK, Holmboe-Ottesen G \& Wandel M (2010) Associations between food patterns, socioeconomic position and working situation among adult, working women and men in Oslo. Eur J Clin Nutr 64, 1150-1157.

33. Bentzen J \& Smith V (2004) Are the fluctuations in the consumption of alcohol pro- or counter-cyclical? Empirical evidence from the Scandinavian countries using long-run time series data. Paper presented at the VDQS Oenometri XI Conference, Dijon, France, 21-22 May 2004.

34. Engeset D, Alsaker E, Ciampi A et al. (2005) Dietary patterns and lifestyle factors in the Norwegian EPIC cohort: the Norwegian Women and Cancer (NOWAC) study. Eur J Clin Nutr 59, 675-684. 
35. Mishra GD, McNaughton SA, Ball K et al. (2010) Major dietary patterns of young and middle aged women: results from a prospective Australian cohort study. Eur J Clin Nutr 64, 1125-1133

36. Markussen MS, Veierod MB, Sakhi AK et al. (2015) Evaluation of dietary patterns among Norwegian postmenopausal women using plasma carotenoids as biomarkers. Br J Nutr 113, 672-682.

37. Charreire H, Kesse-Guyot E, Bertrais S et al. (2011) Associations between dietary patterns, physical activity (leisure-time and occupational) and television viewing in middle-aged French adults. Br J Nutr 105, 902-910.

38. van Dam RM, Grievink L, Ocke MC et al. (2003) Patterns of food consumption and risk factors for cardiovascular disease in the general Dutch population. Am J Clin Nutr 77, $1156-1163$.

39. Kant AK (2004) Dietary patterns and health outcomes. J Am Diet Assoc 104, 615-635.

40. Nordic Council of Ministers (2014) Nordic Nutrition Recommendations 2012: Integrating Nutrition and Physical Activity, 5th ed. Copenhagen: Nordisk Ministerråd.

41. Kesse-Guyot E, Bertrais S, Peneau S et al. (2009) Dietary patterns and their sociodemographic and behavioural correlates in French middle-aged adults from the SU.VI. MAX cohort. Eur J Clin Nutr 63, 521-528.

42. Harrington JM, Dahly DL, Fitzgerald AP et al. (2014) Capturing changes in dietary patterns among older adults: a latent class analysis of an ageing Irish cohort. Public Health Nutr 17, 2674-2686.

43. Mishra GD, Prynne CJ, Paul AA et al. (2004) The impact of inter-generational social and regional circumstances on dietary intake patterns of British adults: results from the 1946 British Birth Cohort. Public Health Nutr 7, 737-744.
44. Hart CL, Davey Smith G, Upton MN et al. (2009) Alcohol consumption behaviours and social mobility in men and women of the Midspan Family study. Alcohol Alcohol 44, 332-336.

45. Mashta O (2009) Middle classes in Britain drink most alcohol, but smoking is at lowest recorded level. BMJ 338, b312.

46. Connor Gorber S \& Tremblay MS (2010) The bias in selfreported obesity from 1976 to 2005: a Canada-US comparison. Obesity (Silver Spring) 18, 354-361.

47. Hebert JR, Clemow L, Pbert L et al. (1995) Social desirability bias in dietary self-report may compromise the validity of dietary intake measures. Int J Epidemiol 24, 389-398.

48. Scagliusi FB, Polacow VO, Artioli GG et al. (2003) Selective underreporting of energy intake in women: magnitude, determinants, and effect of training. J Am Diet Assoc 103, $1306-1313$.

49. Rothman KJ, Greenland S \& Lash TL (2008) Modern Epidemiology, 3rd ed. Philadelphia, PA: Lippincott Williams \& Wilkins.

50. Patterson RE, Kristal AR, Tinker LF et al. (1999) Measurement characteristics of the Women's Health Initiative food frequency questionnaire. Ann Epidemiol 9, 178-187.

51. Neuhouser ML, Tinker L, Shaw PA et al. (2008) Use of recovery biomarkers to calibrate nutrient consumption selfreports in the Women's Health Initiative. Am J Epidemiol 167, 1247-1259.

52. Northstone K, Ness AR, Emmett PM et al. (2008) Adjusting for energy intake in dietary pattern investigations using principal components analysis. Eur J Clin Nutr 62, 931-938.

53. Smith AD, Emmett PM, Newby PK et al. (2013) Dietary patterns obtained through principal components analysis: the effect of input variable quantification. BrJ Nutr 109, 1881-1891. 